\title{
Emissions and low-carbon development in Guangdong-Hong Kong-Macao Greater Bay Area cities
} and their surroundings

Ya Zhou ${ }^{1,2,3}$, Yuli Shan ${ }^{3, *}$, Guosheng Liu ${ }^{1, *}$, Dabo Guan ${ }^{3,4}$

1 School of Management, Guangdong University of Technology, Guangzhou, 510520, China

2 Big Data Strategic Research Institute, Guangdong University of Technology, Guangzhou, 510006, China

3 Water Security Research Centre, Tyndall Centre for Climate Change Research, School of International Development, University of East Anglia, Norwich NR4 7TJ, UK

4 Department of Earth System Sciences, Tsinghua University, Beijing 100080, China

* Corresponding address: y.shan@uea.ac.uk (Yuli Shan); gliu@gdut.edu.cn (Guosheng Liu)

\begin{abstract}
Cities are the major contributors to energy consumption and $\mathrm{CO}_{2}$ emissions, as well as being leading innovators and implementers of policy measures in climate change mitigation. Guangdong-Hong Kong-Macao Greater Bay Area (GBA) is an agglomeration of cities put forward by China to strengthen international cooperation among "Belt and Road" countries and promote low-carbon, inclusive, coordinated and sustainable development. Few studies have discussed the emission characteristics of GBA cities. This study, for the first time, compiles emission inventories of 11 GBA cities and their surroundings based on IPCC territorial emission accounting approach, which are consistent and comparable with the national and provincial inventories. Results show that (a) total emissions increased from $426 \mathrm{Mt}$ in 2000 to $610 \mathrm{Mt}$ in 2016, while emissions of GBA cities increased rapidly by $6.9 \%$ over 2000-2011 and peaked in 2014 (334 Mt); (b) raw coal and diesel oil are the top two emitters by energy type, while energy production sector and tertiary industry are the top two largest sectors; (c) GBA cities take the lead in lowcarbon development and emitted $4 \%$ of total national emissions and contributed $13 \%$ of national GDP with less than a third of national emission intensities and less than three-quarters of national per capita emissions; (d) Macao, Shenzhen and Hong Kong have the top three lowest emission intensity in the country; (e) most of GBA cities are experiencing the shift from an industrial economy to a service economy, while Hong Kong, Shenzhen, Foshan and Huizhou reached their peak emissions and Guangzhou, Dongguan and Jiangmen remained decreasing emission tendencies; (g) for those coal-dominate or energy-production cities (i.e. Zhuhai, Zhongshan, Zhaoqing, Maoming, Yangjiang, Shanwei, Shaoguan and Zhanjiang) in mid-term industrialization, total emissions experienced soaring increases. The emission inventories provide robust, self-consistent, transparent and comparable data support for identifying spatial-temporal emission characteristics, developing low-carbon policies, monitoring mitigation progress in GBA cities as well as further emissions-related studies at a city-level. The low-carbon roadmaps designed for GBA cities and their surroundings also provide a benchmark for other
\end{abstract}


developing countries/cities to adapting changing climate and achieve sustainable development.

Keywords: Guangdong-Hong Kong-Macao Greater Bay Area; Belt and Road Initiative; $\mathrm{CO}_{2}$ emissions; low-carbon development pathways; urban agglomeration

\section{Introduction}

According to latest statistics of the International Energy Agency (IEA), global energy demand rose by $2 \%$ in 2017 , while $72 \%$ of the demand growth was met by oil, natural gas and coal. Meanwhile, the energy-related $\mathrm{CO}_{2}$ emission grew by $1.4 \%$ and reached a historic high of 32.5 gigatonnes (Gt) IEA [1]. Such huge amounts of fossil fuel-related $\mathrm{CO}_{2}$ emission have forced decision makers to implement climate change mitigation actions and achieve sustainable development. As centres of commerce and industry of regions or countries, cities are the major contributors to energy consumption and $\mathrm{CO}_{2}$ emissions [2-4]. In recent decades, with rapid population transfer as well as accelerating urbanisation processes, the cities' energy demand and human-induced $\mathrm{CO}_{2}$ emissions have experienced continuous increases[1,5]. Urban contributed more than $70 \%$ of global $\mathrm{CO}_{2}$ emissions as well as two-thirds of global energy consumption [6]. Meanwhile, cities are regarded as the leading innovators and implementers of policy measures in climate change mitigation and low-carbon development [79]. Bay area comprises scores of cities surrounding the bay, featuring developed service industries, major global financial centres and transportation junctions. With the clustering impact of urban agglomeration, bay area undertakes diverse (i.e. technological, institutional, industrial and financial) innovation activities and increasingly exerts an active role in global economic development. Bay area is regarded as key player in the transition to sustainable energy system and mitigation of rapid climate change impacts [10]. It is therefore essential that more endeavours be taken to play leadership roles of urban agglomeration in $\mathrm{CO}_{2}$ emission mitigation.

Establishing accurate emission inventories and understanding the cities' emission characteristics is the first step to conduct climate change mitigation and adaption actions at a city-level. Emission inventories are regarded as important tools for authorities in $\mathrm{CO}_{2}$ emission mitigation policy formulation and implementation [11-17]. Citylevel $\mathrm{CO}_{2}$ emission inventories were compiled by applying bottom-up and top-down approaches from spatial and temporal perspectives [18-24]. For example, Dhakal [25] selected 35 key Chinese provincial capitals/cities and calculated total energy consumption, $\mathrm{CO}_{2}$ emissions and average carbon intensity of these cities. He found that these cities consumed $40 \%$ of the total commercial energy of nation and emitted $\mathrm{CO}_{2}$ at similar levels. Dodman [11] produced urban greenhouse gas emission inventories by city and sector, while the main drivers for high levels of greenhouse gas production were identified, and the role and potential for cities to reduce global greenhouse gas emissions were examined. Brondfield [19] modelled two on-road $\mathrm{CO}_{2}$ emission inventories scaling approach and applied it to Boston (USA) for capturing urban road-type spatial heterogeneity. Liu, Liang [26] complied topdown energy-related greenhouse gas emission inventories of the four Chinese mega-cities during 1995-2009. Sugar, Kennedy [20] provided comprehensive and detailed emissions inventories for Shanghai, Beijing, and Tianjin in 2006, compared to ten other global cities and discussed the issues concerning low-carbon growth in China. 
Kennedy [21] calculated the greenhouse inventories of global 22 cities using a bottom-up approach under the United Framework Convention on Climate Change (UNFCC), variations of emission mitigation strategies result from the differences in cities characteristics were discussed. $\mathrm{Xu}, \mathrm{Huo}$ [27] estimated the $\mathrm{CO}_{2}$ emissions derived from the fossil fuel combustion and industrial processes of 18 central cities in China between 2000 and 2014. Shan Y. [9] investigated the $\mathrm{CO}_{2}$ emissions of 182 cities in China and explored their emission reduction capacities. Markolf, Matthews [24] calculated production-based GHG emissions for the 100 most populated metropolitan areas in the United States in 2014 based on national datasets. Wang and Liu [28] assessed city-level $\mathrm{CO}_{2}$ emission based on DMSP/OLS 'city lights' satellite data. Generally, the bottom-up approach estimated emissions resulting from local energy activities and technologies at the site location based on spatial and geographical techniques and/or night-light data. However, data collection and accounting procedures differ from site to site, and from person to person, compiled inventories based on different sources, scope and sector sets were not consistent and comparable[4]. In comparison, the top-down approach mainly focused on economic modelling (i.e., computable general equilibrium, input-output method), emissions were calculated at the headquarters level. It may lead to errors when aggregated data do not accurately reflect location conditions[16]. Moreover, most of the previous city-level emission inventories were not accorded with national/provincial inventories and cannot be re-use and cross-validated.

As one of China's current national key economic development strategies, the Guangdong-Hong Kong-Macao Greater Bay Area (GBA) was first highlighted in the $13^{\text {th }}$ Five-Year Plan (2016-2020) in 2016. The new initiative is an updated version of previous regional development initiatives, such as the Pearl River Delta and the Pan-Pearl River Delta [29]. GBA consists of cities of " $9+2$ ", that is nine cities in Guangdong Province (Guangzhou, Shenzhen, Zhuhai, Dongguan, Huizhou, Zhongshan, Foshan, Zhaoqing and Jiangmen from Pearl River Delta), as well as two Special Administrative Regions (Hong Kong and Macao). Local authorities have implemented a series of lowcarbon policies and each city has their own specific development goal in GBA development plan (as shown in Table 3) [30]. The detailed rules and related policies of GBA should be released in 2018[31].GBA covers less than one percent of the country's land area, it created 13\% of the national Gross Domestic Product (GDP) in 2016 with only $5 \%$ of total population[32]. With competitive key industries on the global stage, such as manufacturing (hightech), transportation (sea and air cargo services), trade-related services (sourcing, trading, freight-forwarding, finance) as well as the digital and innovation industry, GBA urban agglomeration intends to highlight the region's role and aspiration in the global economic supply chain. In addition, the GBA serves as a major international land and maritime corridor connecting countries along the Silk Road Economic Belt (Central Asia and Europe) and Maritime Silk Road (South Asia, Oceania to Africa and the Middle East) to boost global trade liberalization. The GBA plays significant roles in promoting global low-carbon, sustainable and coordinated development. $\mathrm{CO}_{2}$ emission inventories are a foundation for identifying the sectors, sources and activities responsible for emissions, generating GBA low carbon development strategies, and monitoring progress towards the climate change mitigation policy goal. However, seldom studies focused on air pollutant emissions from San Francisco Bay Area 
$[33,34]$. Few studies have discussed the emission inventories and characteristics of GBA cities.

Table 1 Implemented low carbon-related policy and development goal of 11 GBA cities

\begin{tabular}{|c|c|c|}
\hline City & Implemented low carbon-related policy & Development goal \\
\hline Hong Kong & $\begin{array}{l}\text { HK Climate Change Action Plan } 2030 \\
12^{\text {th }} \text { Five-year-plan on SZ industrial and commercial energy } \\
\text { conservation } \\
\text { Mid- and long-term plans on SZ low carbon development } \\
(2011-2020)\end{array}$ & Global financial centre and logistics centre \\
\hline Shenzhen & $\begin{array}{l}\text { Provisions of Carbon Emissions Management of the SZ Special } \\
\text { Economic Zone } \\
\text { Special Funds for SZ renewable energy and new energy vehicle } \\
\text { development } \\
\text { SZ Sustainable development plan (2017-2030) }\end{array}$ & International innovation service centre \\
\hline Guangzhou & $13^{\text {th }}$ Five-year-plan on GZ energy saving and carbon reduction & Three international strategic hubs \\
\hline Dongguan & $13^{\text {th }}$ Five-year-plan on DG energy saving (2016-2020) & International manufacturing service centre \\
\hline Foshan & $\begin{array}{l}\text { FS constructing low carbon city plan } \\
12^{\text {th }} \text { Five-year-implementation-plan on } \mathrm{ZH} \text { greenhouse gas } \\
\text { emission control } \\
13^{\text {th }} \text { Five-year-plan on ZH green and low carbon development } \\
13^{\text {th }} \text { Five-year-implementation-plan on ZS greenhouse gas } \\
\text { emission control }\end{array}$ & $\begin{array}{l}\text { International industrial manufacturing centre } \\
\text { Expanding bridgehead and the innovation } \\
\text { plateau }\end{array}$ \\
\hline Zhongshan & $\begin{array}{l}12^{\text {th }} \text { Five-year-plan on low carbon development } \\
\text { Interim procedures for ZS low carbon development special } \\
\text { funds }\end{array}$ & State-level advanced manufacturing base \\
\hline Macao & Macao environmental protection plan (2010-2020) & World tourism leisure centre \\
\hline Huizhou & HZ low carbon ecology plan (2014-2030) & $\begin{array}{l}\text { Ecological tour of "green city", taking ecological } \\
\text { responsibility of the Greater Bay Area }\end{array}$ \\
\hline Jiangmen & JM city low carbon development strategy plans (2010-2020) & State-level advanced manufacturing base \\
\hline Zhaoqing & ZQ new area low carbon development subject plan (2012-2030) & $\begin{array}{l}\text { Agglomeration area of upgrading traditional } \\
\text { industries }\end{array}$ \\
\hline
\end{tabular}

Therefore, in order to fill the gap, for the first time, we conduct time-series $\mathrm{CO}_{2}$ emission inventories of 11 GBA cities and 12 surroundings cities based on IPCC territorial emission accounting approach. Our inventories are constructed by 17 fossil fuels, 47 socio-economic sectors, and 7 industrial processes, which are consistent and comparable with the national and provincial inventories. We provide all the primary data and results on www.ceads.net for freely download, making the emission data transparent, verifiable, and re-usable for the academic society and policy stakeholders. At last, the integrated socio-economic-emission analysis of GBA and 
their surroundings could be conducted. Overall low-carbon roadmaps for the cities are figured based on current emission characteristic, urbanisation process, industrial maturity and resource availability, and provide a benchmark for other urban agglomeration as well as cities along the Belt and Road.

\section{Methods and data sources}

In this study, based on sectoral approach of the Intergovernmental Panel on Climate Change (IPCC) method, administrative territorial-based $\mathrm{CO}_{2}$ emissions of GBA cities are calculated from production side [35]. According to Shan, Guan [4], $\mathrm{CO}_{2}$ emissions emitted by 17 kinds of fossil fuel consumption and 7 industrial processes within the city boundary are considered (see Table S1 and Table S2 in the Supporting Information). The emissions from electricity generation are calculated with primary energy input (e.g. raw coal, fuel oil and diesel oil). Thus, emissions produced outside the city boundaries, such as energy and electricity import are not taken into consideration. Energy used as chemical raw material and loss during transportation are removed from the total energy consumption to avoid double counting [36, 37].

\subsection{Energy consumption}

According to the IPCC [35], the fossil fuel-related emission can be calculated as energy activity (energy consumption) of socioeconomic sectors multiplied by the emission factors (see Equation 1).

$$
C E_{\text {energy }}=\sum_{i=1}^{17} \sum_{j=1}^{47} C E_{i j}=\sum_{i=1}^{17} \sum_{j=1}^{47} A D_{i j} \cdot N C V_{j} \cdot C C_{j} \cdot O_{i j}
$$

Equation 1

where $i$ presents energy type, $j$ shows socioeconomic sector (see Table $\mathrm{S} 1$ ). $\mathrm{CE}_{i j}$ means $\mathrm{CO}_{2}$ emission by energy type $i$ and socioeconomic sector $j . A D_{i j}$ denotes the activity data, namely fossil fuel consumption. $N C V_{j}, C C_{j}$, and $O_{i j}$ are known as emission factors, which respectively denote net caloric value, carbon content, and the oxygenation efficiency. These three parameters were collected from Liu, Guan [38], which are thought to more accurate regarding China's energy consumption.

In this study, 17 kinds of fossil fuels are divided into three categories: coal, oil and gas. 39 sub-sectors of the industrial sectors are classified according to the system of Nation Economic Accounting [39]. We divide the 39 sectors into 4 categories: energy production, heavy manufacturing, light manufacturing, and high-tech industries. The energy production category includes 5 sectors which produce both primary and secondary energy types, while high-tech category refers to 5 sectors aiming at high and new technical industries. The remaining 29 sectors belong to manufacturing sectors, including both heavy and light manufacturing sectors (see Table S3). We define the heavy manufacturing category to include 16 sectors that input energy to produce intermediate products, such as ferrous metals mining and dressing, and non-metal mineral products. 13 sectors are classified as light 
manufacturing sectors, which mainly produce final products such as food processing and furniture manufacturing.

\subsection{Industrial processes}

Industrial processes, such as silicon metal, ferro-unclassified, ferrochromium, ammonia, soda ash, cement and lime production, contribute more than $95 \%$ of total process-related emission in China [40-42]. $\mathrm{CO}_{2}$ emission of industrial processes indicate the emissions emitted from chemical reactions during 7 production processes, while energy used by industry are not taken into consideration. The process-related $\mathrm{CO}_{2}$ emissions can be calculated in Equation 2.

$$
C E_{\text {process }}=\sum_{t=1}^{7} C E_{t}=\sum_{t=1}^{7} A D_{t} \cdot E F_{t}
$$

Equation 2

where $t$ presents industrial process, $C E_{t}$ and $E F_{t}$ respectively denote the process-related $\mathrm{CO}_{2}$ emissions and emission factors, $A D_{t}$ presents the industrial products. Most of the emission factors for industrial processes were sourced from the IPCC [35], while the emission factor for cement production was collected from Liu, Guan [38].

\subsection{Data sources and verification}

Table 2 provides the socioeconomic indexes of 23 cities. The annual data of population, GDP (at 2015 constant price), industry output as well as other socioeconomic data of 21 Guangdong cities were sourced from each city's statistical yearbook from 2001 to 2017. Activity data $\left(A D_{i j}\right.$ and $\left.A D_{t}\right)$ were calculated based on energy balance table (EBT) and industry sectoral energy consumption of each city. Due to the limitations in data quality, energy consumption data of some individual years are missing, such as Shenzhen (2005-2008) and Dongguan (20012014) and Chaozhou (2000- 2003), Meizhou (2001), Zhangjiang (2001), Shantou (2003), Jiangmen (2005) and Yunfu $(2001,2005)$, and associated emission inventories could not be constructed. Most cities except for Guangzhou (2000-2013), Qingyuan (2000-2014) and Yangjiang (2006-2016) do not have energy balance table in their statistical yearbooks. We follow our previous research to scale down the provincial EBTs of Guangdong to get the data for other cities [4]. The EBTs of Guangdong were collected from the National Bureau of Statistics (NBS) [43]. Total emissions of Hong Kong and Macao from 2000 to 2016 were collected from Emissions Database for Global Atmospheric Research (EDGAR) [44]. The population and GDP (at 2015 constant price) time series data of Hong Kong and Macao respectively come from the database of Hong Kong's Census and Statistics Department [45] and Macao's Statistics and Census Service[46]. The exchange rates of Hong Kong Dollar (HKD) and Macao Pataca (MOP) to Chinese Yuan (CNY) were collected from China statistical yearbook [47] and China Foreign Exchange Trade System [48].

$\mathrm{CO}_{2}$ emissions of 21 cities could be verified in the whole province and time series instead of single year and single 
city. Total emissions were compared firstly in 17 years' time-series, those outliers which involved choosing the wrong case or input errors in the particular year could be found directly. The emissions by energy types were checked secondly across the various energy types and time series, those mistakes of energy consumption of each energy type in EBTs could be found quickly. Total emissions by sectors should be examined finally to identify those typing mistakes of specific energy consumption by each sector in EBTs. This verification approach can also be useful for adjust those cities having similar size and industrial structure with huge different total emissions.

\subsection{Uncertainty analysis}

Uncertainties associated with modelling inputs and parameters can induce potential significant impact on generating a precise estimation for carbon emissions. A number of implications associated with incomplete datum, economic fluctuations, environmental factors, and subjective judgments and data quality issues may exist [49]. Uncertainties may exist in emission factors and energy activities. In this study, the Monte Carlo method recommended by IPCC [35] is adopted to assess the uncertainties in the cities' emissions. The uncertainties are presented the intervals with lower and upper bounds of a certain confidence interval $(\mathrm{Cl})$ around our central estimates. All the input parameters of activity data and emission factors, with assumed normal distributions, are placed in a Monte Carlo framework. 20,000 simulations were performed to analyse the uncertainty of estimated emissions by sectors. Both activity data and emission factors are assumed to be normally distributed [38]. Coefficients of variations ( $C V$, standard deviation divided by the mean) were collected from literature: the activity data have $\mathrm{CV}$ ranging from $5 \%$ to $30 \%$ depending on the sectors [35, 50-52]; the emission factors have CV of $3 \%$ (coal), $1 \%$ (oil) and $2 \%$ (natural gas). Results indicate that $97.5 \%$ uncertainties ( $\pm 47.5 \% \mathrm{Cl}$ around the central estimate) of 21 cities fall in [-5.6\%, 7.8\%]. The highest uncertainty appears in Shantou in 2013 [-5.6\%, 5.7\%], while the lowest appears in Jieyang in 2000 [-1.1\%, 1.1\%].

\section{Results and discussions}

\section{1 $\mathrm{CO}_{2}$ emissions of GBA cities and their surroundings}

By calculating 21 Guangdong cities and incorporating Hong Kong and Macao, $\mathrm{CO}_{2}$ emission inventories of GBA and their surroundings from 2000 to 2016 have been complied (see Table 3). Total emissions of 23 cities increased from $426 \mathrm{Mt}$ in 2000 to $610 \mathrm{Mt}$ in 2016. Guangzhou, Shaoguan, Hong Kong are top three emitters and respectively produced $66(12 \%), 52.3(9 \%)$ and $47(8 \%)$ million tonnes $\mathrm{CO}_{2}$, equal to a quarter of total emissions. GBA cities contributed $16.4 \%$ higher emissions than the surrounding cities. 
Table 2 Emission-socio-economic index of 23 cities, 2015

\begin{tabular}{|c|c|c|c|c|c|c|c|c|}
\hline City & Region & City group & $\begin{array}{l}\text { Population } \\
\left(10^{4}\right)\end{array}$ & $\begin{array}{l}G D P \\
\left(¥ 10^{8}\right)\end{array}$ & $\begin{array}{l}\text { Per capita GDP } \\
(¥)\end{array}$ & $\begin{array}{l}\text { Total emission } \\
\text { (million tons) }\end{array}$ & $\begin{array}{l}\text { Emission intensity } \\
\text { (tons } / ¥ 10^{4} \text { ) }\end{array}$ & $\begin{array}{l}\text { Emission } \\
\text { characteristics }\end{array}$ \\
\hline Guangzhou & Pearl River Delta & GBA & 13501 & 1810 & 134066 & 67.33 & 0.37 & Decreasing \\
\hline Shenzhen & Pearl River Delta & GBA & 11379 & 1750 & 153821 & 29.89 & 0.17 & Peak \\
\hline Foshan & Pearl River Delta & GBA & 7431 & 800 & 107716 & 38.49 & 0.48 & Peak \\
\hline Dongguan & Pearl River Delta & GBA & 8254 & 628 & 76024 & 42.36 & 0.67 & Decreasing \\
\hline Zhuhai & Pearl River Delta & GBA & 1634 & 203 & 123947 & 17.38 & 0.86 & Quick growth \\
\hline Zhongshan & Pearl River Delta & GBA & 3210 & 301 & 93782 & 11.88 & 0.39 & Quick growth \\
\hline Jiangmen & Pearl River Delta & GBA & 4520 & 224 & 49564 & 24.85 & 1.11 & Peak \\
\hline Zhaoqing & Pearl River Delta & GBA & 4060 & 197 & 48527 & 20.49 & 1.04 & Quick growth \\
\hline Huizhou & Pearl River Delta & GBA & 4756 & 314 & 66029 & 24.69 & 0.79 & Peak \\
\hline Hong Kong & Pearl River Delta & GBA & 7291 & 1927 & 264257 & 46.49 & 0.24 & Peak \\
\hline Macao & Pearl River Delta & GBA & 647 & 294 & 455314 & 2.90 & 0.10 & Quick growth \\
\hline Shantou & Eastern Region & Other & 5552 & 187 & 33645 & 23.76 & 1.27 & Peak \\
\hline Chaozhou & Eastern Region & Other & 2641 & 91 & 34467 & 17.30 & 1.90 & Decreasing \\
\hline Jieyang & Eastern Region & Other & 6059 & 189 & 31194 & 18.17 & 0.96 & Peak \\
\hline Shanwei & Eastern Region & Other & 3022 & 76 & 25221 & 16.93 & 2.22 & Quick growth \\
\hline Zhanjiang & Western Region & Other & 7241 & 238 & 32867 & 24.31 & 1.02 & Quick growth \\
\hline Maoming & Western Region & Other & 6081 & 245 & 40219 & 20.45 & 0.84 & Quick growth \\
\hline Yangjiang & Western Region & Other & 2511 & 125 & 49777 & 18.03 & 1.44 & Quick growth \\
\hline Shaoguan & Northern Region & Other & 2932 & 115 & 39228 & 50.78 & 4.41 & Peak \\
\hline Qingyuan & Northern Region & Other & 3835 & 128 & 33325 & 23.37 & 1.83 & Peak \\
\hline Yunfu & Northern Region & Other & 2461 & 71 & 28984 & 10.90 & 1.53 & Peak \\
\hline Meizhou & Northern Region & Other & 4341 & 96 & 22111 & 27.81 & 2.90 & Decreasing \\
\hline Heyuan & Northern Region & Other & 3074 & 81 & 26357 & 7.13 & 0.88 & Peak \\
\hline
\end{tabular}


So as to better understand the emission characteristics of 23 cities, we divided total emissions calculated by the gross domestic product (GDP) and obtained production-based emission intensities of 23 cities. Figure 1 presents the locations and emission intensities of GBA and other cities in 2015. The color on the map shows the classification of GBA cities (red) and other cities in Guangdong (blue), while the shade of colour displays the emission intensities. Emission intensities of GBA cities varied from 0.1 (Macao) to 1.1 (Jiangmen) tons per $¥ 1,000$, while those of other cities changed from 0.8 (Maoming) to 4.3 (Shaoguan) tons per $¥ 1,000$. Macao, Shenzhen and Hong Kong are driven serviced-based economy and have top-three lowest emission intensities. In contrast, Shaoguan and Meizhou are centres of Guangdong heavy manufacturing cities and have the first and second highest emission intensities.

After dividing total emissions by the population, per capita production-based emissions could be obtained. Figure 1 a) to c) show respectively total emissions, per capita emissions and emission intensities of GBA and their surroundings in the period of 2000-2016. Result indicates that total emissions of GBA cities increased rapidly by 7\% in the period 2000-2011 and peaked in 2014 (334 Mt), while those of other cities revealed a faster trend by $14 \%$ and peaked in 2011. As 5 GBA cities and 2 other cities lack of energy activity data in 2004, total emissions presented an obvious fluctuation in 2004, especially for GBA cities (The same fluctuation occurs in emission by energy types and sectors as shown in Figure 2). Emission intensity of GBA reached its peak in 2005 (0.8 tons per $¥ 1,000$ ) and decreased to 0.4 tons per $¥ 1,000$ in 2016 . Emission intensities of GBA cities were $75 \%$ lower than the surroundings, and 33\% lower than those of Guangdong Province. Per capita emissions of GBA cities experienced a rapid increase over 2000-2006, reached a plateau (6.2 tonnes) in 2007, and fell to 4.9 tonnes with an annual rate of $3 \%$. For other cities, per capita emissions tended to a rapid increase in past 17 years and exceeded those of GBA cities since 2014. Per capita emissions of GBA cities were $5 \%$ lower than those of surroundings, and $2 \%$ lower than those of Guangdong Province.

In order to further discuss $\mathrm{CO}_{2}$ emissions of $\mathrm{GBA}$ and their surroundings at the aggregate national level, we compared the emission intensity with other Chinese cities[9]. Results indicate that Macao, Shenzhen and Hong Kong have the lowest emission intensity in the country, emission intensity of GBA cities is $88 \%$ below the average of Chinese cities (3.2 tons per $¥ 1,000$ ) and remain within the top $10 \%$ of performers at a national level. It demonstrated that GBA cities take the lead in low-carbon development attributed to technological advancement, industrial transition and government incentives. Shaoguan and Meizhou have high emission intensity, respectively accounting for $76 \%$ and $49 \%$ of national level, while the other cities is $60 \%$ lower than the average national level, staying the top $[6,49] \%$. Generally, GBA emitted $4 \%$ of total national emissions and contributed $13 \%$ of national GDP with less than a third (29\%) of national emission intensities and less than three-quarters (73\%) of national per capita emissions. Other cities supported GBA cities with raw materials, processing products, power and labour, emitting 3\% of total national emissions and occupying $2 \%$ of national GDP with medium national emission intensity level. 
Table 3 Time-series total emissions of GBA cities and their surroundings, 2000-2016 (million tonnes)

\begin{tabular}{|c|c|c|c|c|c|c|c|c|c|c|c|c|c|c|c|c|c|}
\hline City & 2000 & 2001 & 2002 & 2003 & 2004 & 2005 & 2006 & 2007 & 2008 & 2009 & 2010 & 2011 & 2012 & 2013 & 2014 & 2015 & 2016 \\
\hline Guangzhou & 46.44 & 47.02 & 51.02 & 58.01 & 70.97 & 80.47 & 82.95 & 86.11 & 88.05 & 91.64 & 99.32 & 103.90 & 99.73 & 100.18 & 66.02 & 67.33 & 65.55 \\
\hline Shenzhen & 12.65 & 15.08 & 17.87 & 22.40 & - & - & - & - & 41.39 & 32.48 & 37.09 & 32.21 & 29.98 & 30.60 & 29.91 & 29.89 & 35.28 \\
\hline Foshan & 28.02 & 29.54 & 31.85 & 32.88 & 36.83 & 40.10 & 42.43 & 44.19 & 40.82 & 35.27 & 37.55 & 45.68 & 43.89 & 40.40 & 41.20 & 38.49 & 39.60 \\
\hline Dongguan & - & - & - & - & - & - & - & - & - & - & - & - & - & - & 46.49 & 42.36 & 41.47 \\
\hline Zhuhai & - & 6.65 & 8.77 & 9.14 & - & 11.35 & 9.92 & 12.44 & 12.16 & 11.85 & 12.76 & 14.53 & 13.50 & 15.93 & 15.88 & 17.38 & 17.71 \\
\hline Zhongshan & 4.86 & 5.10 & 5.69 & - & - & 10.12 & 9.85 & 10.40 & 10.30 & 10.62 & 10.12 & 10.62 & 11.73 & 8.27 & 10.08 & 11.88 & 12.85 \\
\hline Jiangmen & 8.08 & 8.30 & 8.70 & 10.08 & - & 18.30 & 24.21 & 27.88 & 25.70 & 25.08 & 26.79 & 30.11 & 26.01 & 29.01 & 26.47 & 24.85 & 23.66 \\
\hline Zhaoqing & 4.08 & 4.43 & 4.75 & 5.17 & 4.60 & 5.85 & 6.48 & 7.46 & 8.56 & 9.47 & 11.61 & 14.20 & 15.75 & 18.58 & 18.60 & 20.49 & 20.85 \\
\hline Huizhou & 6.47 & 5.60 & 6.92 & 7.69 & 7.90 & 9.22 & 13.28 & 16.23 & 17.13 & 14.75 & 16.20 & 20.40 & 28.99 & 26.32 & 26.91 & 24.69 & 25.27 \\
\hline Hong Kong & 42.13 & 43.35 & 42.05 & 44.71 & 42.77 & 43.10 & 42.56 & 45.59 & 44.58 & 47.76 & 42.43 & 47.38 & 47.43 & 48.42 & 50.24 & 46.49 & 47.07 \\
\hline Macao & 1.33 & 1.54 & 1.57 & 1.63 & 2.02 & 2.08 & 1.91 & 1.89 & 1.93 & 1.97 & 2.13 & 2.30 & 2.34 & 2.56 & 2.71 & 2.90 & 3.11 \\
\hline Shantou & 6.99 & 6.32 & - & 8.94 & 7.40 & 8.12 & 9.84 & 9.49 & 8.84 & 16.24 & 23.57 & 26.81 & 23.83 & 27.41 & 26.51 & 23.76 & 22.21 \\
\hline Chaozhou & - & - & - & 3.68 & 9.29 & 8.02 & 10.14 & 14.86 & 14.53 & 12.40 & 17.47 & 26.28 & 26.02 & 23.63 & 20.93 & 17.30 & 16.50 \\
\hline Jieyang & 1.83 & 1.93 & 2.96 & 2.98 & 2.85 & 5.84 & - & 11.44 & 11.19 & 12.13 & 13.58 & 13.71 & 12.92 & 19.35 & 18.94 & 18.17 & 15.89 \\
\hline Shanwei & 1.75 & 2.20 & 2.06 & 1.81 & 2.15 & 2.61 & 2.34 & 2.58 & 11.10 & 9.77 & 10.18 & 14.27 & 16.09 & 12.79 & 12.42 & 16.93 & 17.51 \\
\hline Zhanjiang & - & 8.02 & 12.38 & 13.54 & 16.09 & 16.65 & 17.57 & 18.18 & 17.73 & 18.79 & 24.48 & 25.86 & 28.71 & 24.17 & 21.67 & 24.31 & 46.25 \\
\hline Maoming & 12.58 & 12.18 & 10.79 & 11.89 & 14.61 & 13.96 & 13.49 & 14.59 & 16.06 & 14.25 & 14.78 & 16.58 & 15.51 & 16.16 & 19.55 & 20.45 & 20.46 \\
\hline Yangjiang & 2.20 & 2.54 & 2.45 & 2.78 & 3.99 & 3.75 & 4.42 & 4.68 & 4.41 & 6.64 & 12.13 & 14.01 & 13.77 & 14.42 & 18.10 & 18.03 & 20.69 \\
\hline Shaoguan & 17.51 & 16.32 & 17.92 & 20.65 & 27.56 & 31.42 & 37.88 & 36.63 & 42.24 & 41.11 & 47.10 & 52.79 & 46.97 & 45.89 & 48.27 & 49.53 & 52.26 \\
\hline Qingyuan & 6.09 & 6.28 & 6.11 & 6.41 & 12.52 & 12.98 & 16.94 & 21.68 & 25.52 & 28.35 & 31.81 & 26.95 & 21.21 & 22.11 & 20.54 & 23.37 & 23.94 \\
\hline Yunfu & - & 4.94 & 4.72 & 7.66 & - & 11.05 & 10.46 & 11.21 & 10.57 & 11.11 & 16.02 & 15.94 & 14.44 & 14.84 & 11.27 & 10.90 & 11.93 \\
\hline Meizhou & 17.60 & 16.35 & 16.96 & 19.22 & - & 17.51 & 23.51 & 25.35 & 25.42 & 29.37 & 29.41 & 28.56 & 28.47 & 30.75 & 29.41 & 27.81 & 22.38 \\
\hline Heyuan & - & 1.43 & 1.60 & 1.83 & 1.66 & 2.43 & 2.56 & 3.15 & 2.95 & 5.48 & 6.98 & 8.77 & 7.43 & 7.05 & 6.89 & 7.13 & 7.74 \\
\hline
\end{tabular}




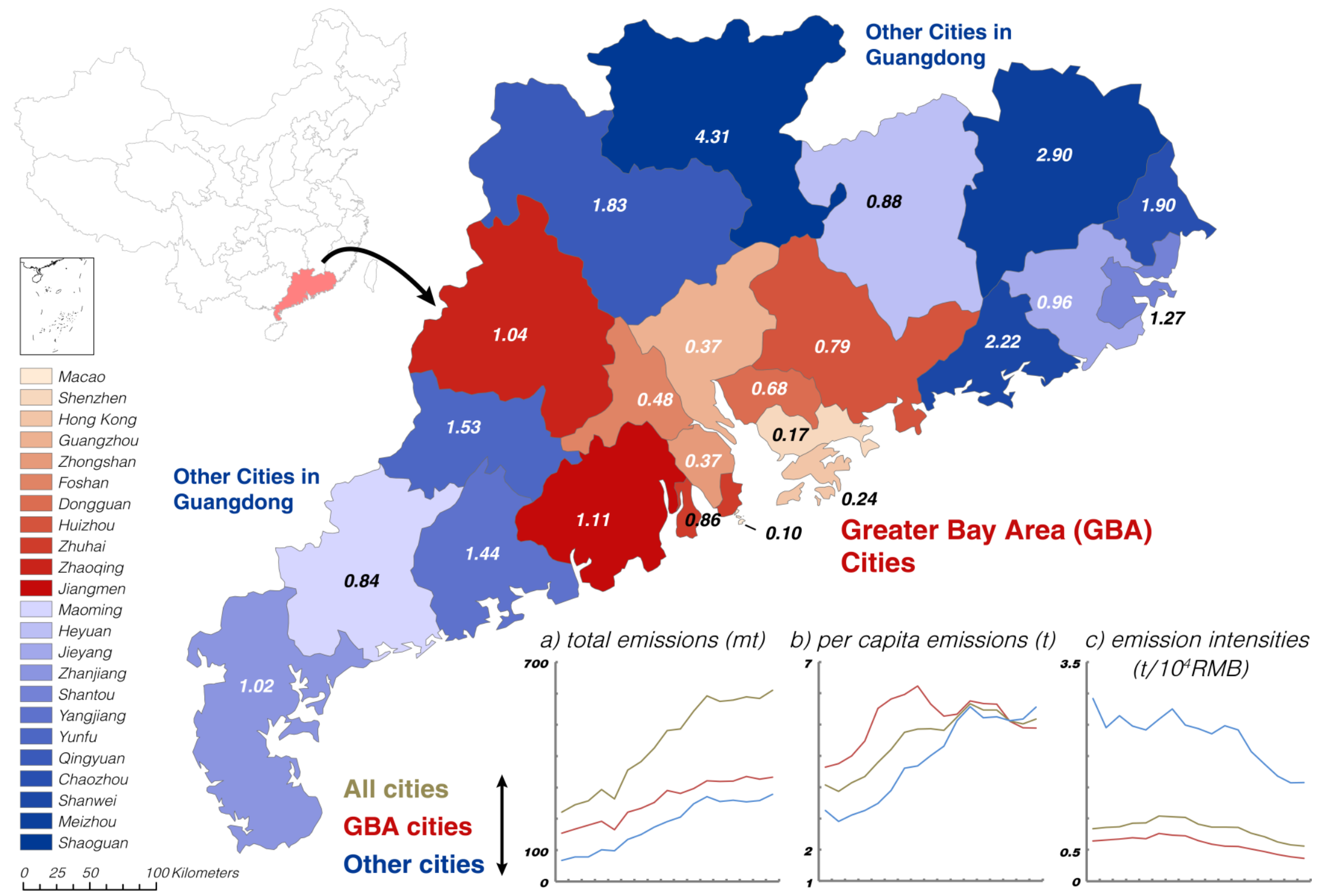

Figure $1 \mathrm{CO}_{2}$ emission intensities of GBA cities and their surroundings (tonnes $\left(\because 10^{4}\right.$ ) 


\section{2 $\mathrm{CO}_{2}$ emissions of GBA cities and their surroundings by energy types and sectors}

Due to resource scarcity, coal and coal-related products (i.e., cleaned coal, other washed coal, briquettes and coke), as well as oil products of GBA and their surroundings mainly rely on imports from domestic and foreign markets. Coal and oil products produced more than four-fifths $\mathrm{CO}_{2}$ of Guangdong Province. Among them, raw coal and diesel oil are the first and second emitters, respectively accounting for $88 \%$ and $32 \%$ of total coal and oil emissions. In past 17 years, coal contribution in total emissions increased from $47 \%$ to $60 \%$, while oil's share declined from $42 \%$ to $26 \%$, gas's share raised from 0 to $4 \%$.

Figure 2 displays the cities' $\mathrm{CO}_{2}$ emissions by energy type over 2000-2016. Emissions by coal, oil and industrial process experienced rapid growth since 2004 and respectively peaked in 2011 (335 Mt) and 2010 (148 Mt), while gas show a sharp rise since 2007. Energy consumption mix of GBA cities was diversified by wide utilization of natural gas, and emissions emitted by coal consumption GBA cities began to slowdown since 2007. Due to larger vehicle numbers, emissions by oil of GBA cities are greater than those of other cities. Emissions by coal consumption of other cities exceeded those of GBA cities in 2007 and reached peak level (190Mt) in 2011 firstly (GBA cities peaked in 2014).

Error! Reference source not found. also shows the total emissions by industrial and non-industrial sectors. 47 socioeconomic sectors were classified into eight categories (seen in Table S3). Industry sectors account for the largest emissions, with $80 \%$ of GD cities, $70 \%$ of GBA cities, $86 \%$ of other cities. Among the industry sector, energy production and heavy manufacturing sector respectively were the first and second contributors of total emissions, respectively occupying $39 \%$ and $20 \%$ of GBA cities. In comparison, other cities have the higher emissions in energy production (50\%) and heavy manufacturing sector (31\%). The service sectors are the third contributors to total emissions. Transportation sectors are the main contributors of service sectors. GBA cities with service sectors have the highest emission (25\%), followed by Guangdong Province (17\%) and other cities (6\%). In summary, total emissions by energy production, light manufacturing, and construction sectors of 23 cities have peak in 2011 (259 Mt), 2014 (40 Mt) and 2013 (3.5 Mt) respectively, while those by heavy manufacturing, service and residential sectors experience rapid increases.

Different from energy production, heavy manufacturing and light manufacturing sectors having onerous demands for various products which involve creation of emissions, the high-tech industry is particularly vulnerable and highly affected by economic, market and policy factors. Electronic information and electric equipment and machinery industries of Guangdong (especially GBA) are indispensable in global industrial chain, various consumer electronics account for a large global market share. Influenced by global financial crisis, a drastic emission slump of high-tech industry sector occurred in 2008. More policy, financial, technical and staff support need to be provided by local authorities to the well-functioning high-tech industry.

In summary, understanding sectors, sources, and activities responsible for $\mathrm{CO}_{2}$ emissions are beneficial for developing cost-effective mitigation policies of sectors. Compiled emission inventories of GBA and their surroundings provide data support for establishing and implementing GBA and Guangdong low-carbon development plan and monitoring the progress in the climate change mitigation of urban agglomeration. 

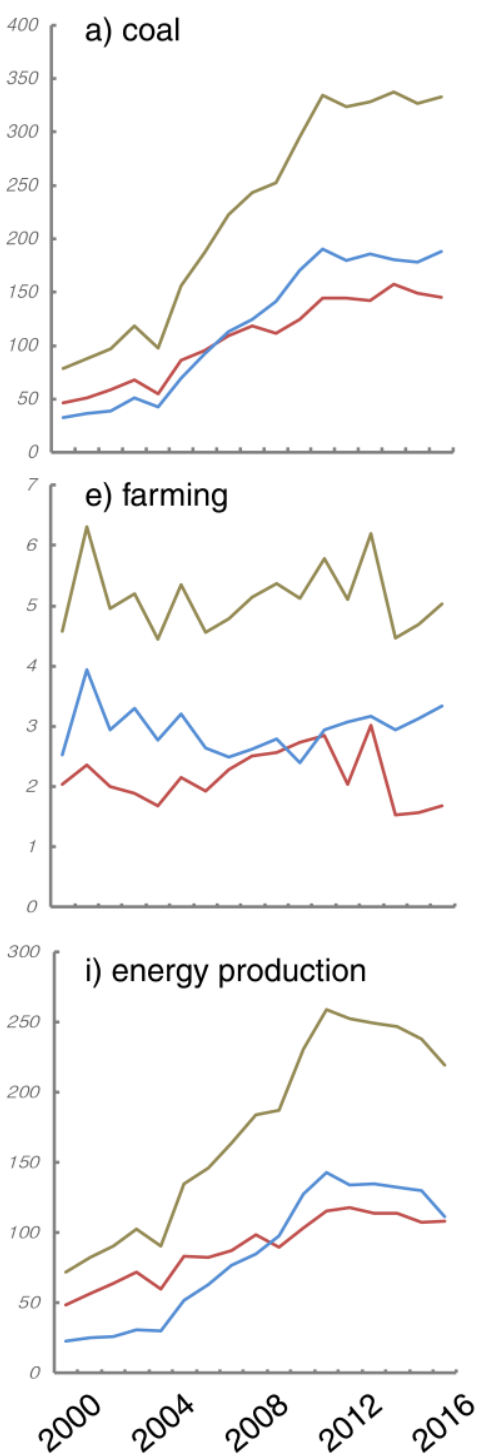
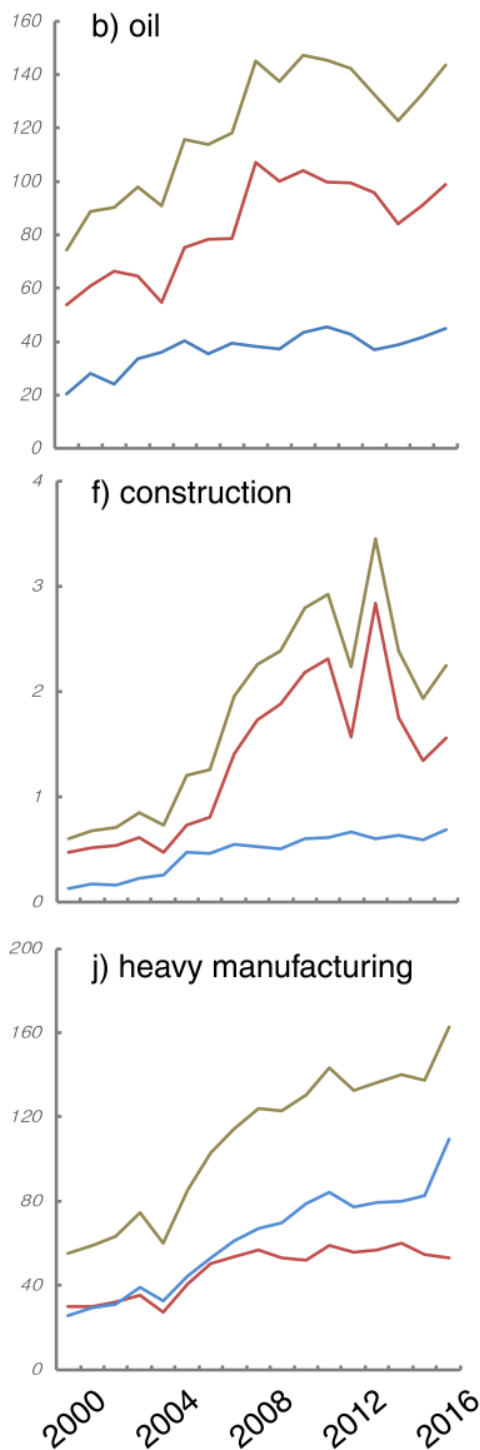
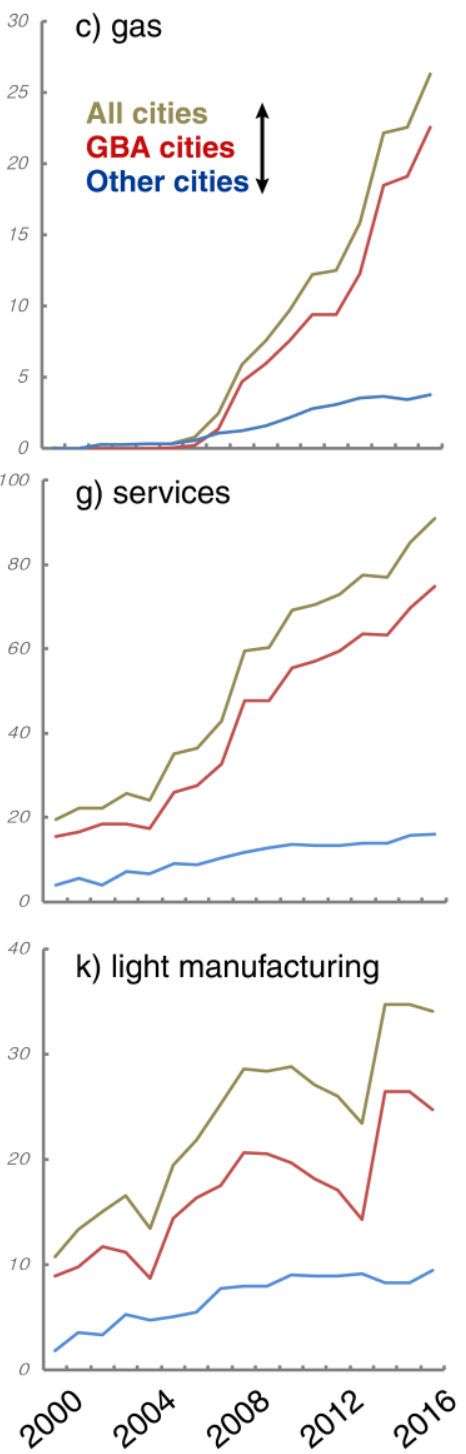

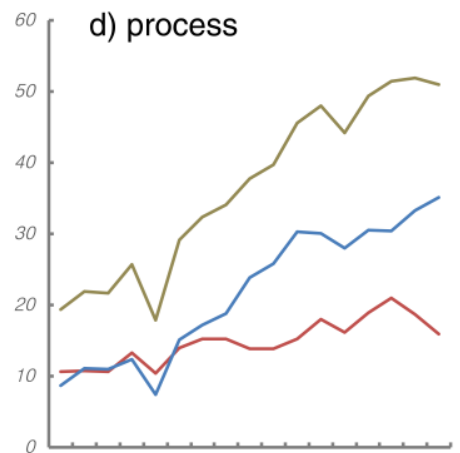

h) residents
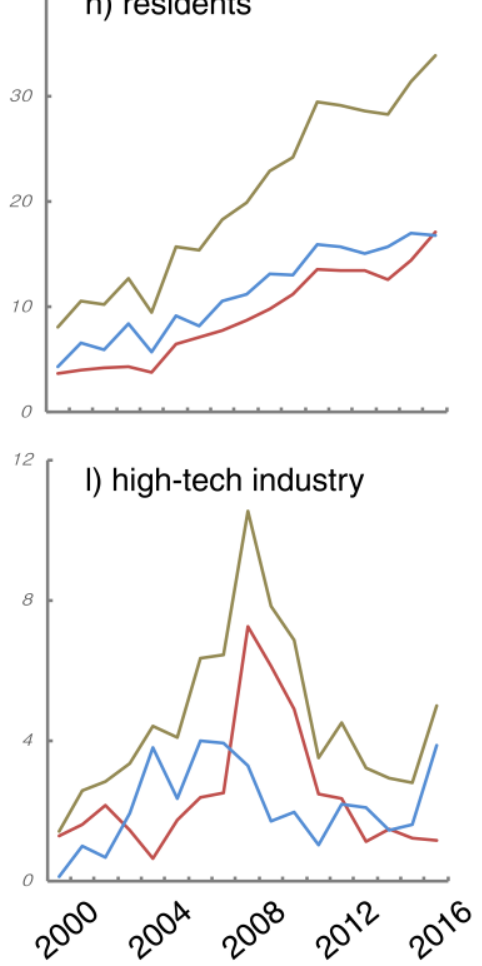

Figure 2 Total $\mathrm{CO}_{2}$ emissions by energy types and sectors of 21 cities (million tonnes). 


\subsection{Emissions characteristics and low-carbon development of key cities}

According to the time-series emission characteristics, 23 cities could be classified into 3 categories, quick growth, peak and decreasing (see Table 2). As core cities of GBA, Guangzhou, Shenzhen and Zhuhai are located in the centre of Pearl River Delta region and are the fastest-growing cities in Guangdong. As its surroundings, Meizhou, Shantou, Yangjiang respectively lie on northern, eastern and western Region and are less well developing regions. Shenzhen, Zhuhai and Shantou are special economic zones (SEZs) of China. From the perspective of emission characteristics, Guangzhou and Meizhou present decreasing, while Shenzhen and Shantou have reached a plateau, Zhuhai and Yangjiang are experiencing quick growth. Thus, based on different geographic locations, cities groups and emission characteristics, we selected Shenzhen, Guangzhou, Zhuhai, Meizhou, Shantou, and Yangjiang as six representative cities to focus on their emission characteristics by energy types and sectors (as shown in Figure S1) and discuss cities' low carbon development pathways.

\subsubsection{Shenzhen}

Shenzhen is the first Special Economic Zone of China and regarded as the one of the fastest growing megacities in the world. Shenzhen has the lowest proportion in total emissions by coal in Guangdong, which is attributed to a series of implemented laws and regulations regarding city's industrial structure and energy mix. Since 2001 Shenzhen started to promote industrial innovation (especially in high-tech and knowledge-intensive industries) and give up heavy and labour-intensive industries. Thus, city's coal and energy production sectors of total emissions reached peak in 2008 (41 Mt and 18Mt) simultaneously. As mechanical and electrical products and photographic equipment were the main exports, city was influenced by global financial crisis in 2008, while city's emission in 2009 appeared a sharp drop. Since 2010 , the city has stepped into the innovation-based development stage, and high-end manufacturing and modern services (represented by finance and Internet) undergone soaring development and became the city's pillar industry.

Tertiary industry accounted for 59\% in Shenzhen's GDP in 2015, while secondary industry for 41\% [53]. The city's services sector presented a tendency to increase, exceeding energy production sectors and became the largest contributors (52\%, energy production for $39 \%$ ) of total emissions since 2012 . Among the tertiary industry, transportation, storage, post and telecommunication services account for the largest contributor of total emissions. Statistics released by the Traffic Management Bureau of the Ministry of Public Security in March 2017 found that there were now 3 million vehicles in Shenzhen (ranked sixth in China) [54]. Thus, different from other 20 cities, oil occupied the biggest proportion (58\%) of city total emissions, followed by coal (21.3\%) and gas (20.8\%). In addition, BYD, the world's largest electric vehicle maker, headquarters in Shenzhen. Due to promotional policies (purchase subsidies and free car license plates), market conditions and better industry chain of new energy vehicles (NEVs), Shenzhen took the lead in the NEV development and was chosen as a pilot for electric transit in 2009. According to the statistics announced by Shenzhen's transport commission in December 2017, the city has transitioned its bus fleet (16,359 buses) to all-electric models, exceeding the numbers of electric buses in metropolitan areas in any other world city[55]. At the end of 2017, Shenzhen had 12,518 taxis and 63\% of them were already electric[55]. The goal of an all-electric taxi fleet is set by 2020 , which will be beneficial to further 
mitigate carbon emissions from transportation.

In addition, the government policy of substituting LNG for fuel oil in oil-fired power plant was implemented in 2010, leading to a surge in liquefied natural gas (LNG) consumption, while citywide coal consumption amount presented a downward trend. Moreover, profited from West-to-East Gas Transport (WEGT) project, LNG replaced coal and fuel oil and became the primary fossil fuel for power generation [56]. Hence, gas contributes to the second largest proportion (21\%) of total emissions in 21 cities. City's power supply structure tends to the transition from coal-dominated into clean energy-dominated (LNG, nuclear fuel and imported electricity produced $83 \%$ of electricity) [49]. There are 3 nuclear power stations (Daya Bay, Ling' ao phase I, Ling'ao phase II) and 6 thousand megawatts units in service, annual electricity generation came to 45 million MWh[57]. Ling'ao phase III nuclear power station is under construction. With the economic competitiveness of annual hours of operation, nuclear power occupies the largest contribution in city's electricity generation[56]. As the first commercial nuclear power station in China, Daya Bay nuclear power station plays significant roles in achieving safe, clean and sustainable electricity supply of Hong Kong for 20 years [58]. Power export contracts based on national and regional energy policies require that $70 \%$ of Daya Bay nuclear power is exported to Hong Kong (national), accounting for $25 \%$ of total power consumption of Hong Kong; rest of Daya Bay nuclear power and mostly of Ling'ao nuclear power are sold to Guangdong power grid (regional) [56]. The rest of nuclear power is directly provided for local end-users, leading to substantial electricity shortage. Such shortage was to be filled by electricity import from Guangdong power grid, accounting for $45 \%$ of citywide total electricity consumption [59]. The first unit of Shenzhen pumped storage power plant $(4 \times 300 \mathrm{MW})$ started to generate electricity at the end of 2018 . City's power consumption mix will be further diversified by renewable energy.

Generally, Shenzhen has contributed to the socioeconomic prosperity and stability of Hong Kong with nuclear power supply for two decades. Thanks to effective regulations and policies of government, optimised industrial structure and clean energy mix, Shenzhen remain high-speed and low-carbon development, contributing the sixth largest total emissions ( 0.4 times of Guangzhou, 1.7 times of Zhuhai) with the second lowest emission intensities ( 0.5 times of Guangzhou, 0.2 times of Zhuhai) and the third largest GDP ( 0.97 times of Guangzhou, 8.6 times of Zhuhai) in the 23 cities.

\subsubsection{Guangzhou}

Guangzhou is the capital of Guangdong Province and one of international metropolises. As the starting point of "Marine Silk Road" and once connection China with the Middle East and Europe, Guangzhou has become the international business centre and international integrated transport hub. The contribution of tertiary industry come to $67 \%$ in Guangzhou's GDP in 2015, while city's secondary industry for 32\%, primary industry for $1 \%$ [53]. In the past, the city focused on textile and light industry; since 2000, the city began to develop heavy manufacturing. Thus, Guangzhou is a traditional industrial city and remained the coal-dominated energy consumption mix since 2000. Vehicle numbers of Guangzhou continued to escalate to 2 million vehicles by the end of March 2017, ranking the fourteenth in China [54]. Oil consumption exceed coal in 2013 and account for the largest total emissions (53\%, followed by Shenzhen, ranking the second in 23 cities), followed by coal (41\%), industrial process (3\%) and gas (2\%). From the perspective of socio-economic sectors, services sectors firstly became biggest emitters in 2014 and was the primary 
contributors (47\%) of total emissions, followed by energy production sectors (35\%), light manufacturing sectors (5\%) and heavy manufacturing sectors (5\%).

The total emissions escalated in the annual average rate of 6\%, peaked in 2011 (104Mt) and plunged to 66 $\mathrm{Mt}$ in 2014. Such a huge fall could be attributed to the fact that many enterprises, involving steel plants, cement plants, metal smelting plants, printing and dyeing mills, tanneries, and chemical fibre factories had to be shut down or relocated to nearby cities (such as Qingyuan, Meizhou) since 2011 to complete the task of closing down backward production facilities of "the Twelfth Five-year Plan" in advance. Guangzhou contributed the largest to total emissions with the second largest GDP and the forth lowest emission intensities. In order to accelerate industrial transformation and upgrading, the Guangzhou government issued the implementation plan of Guangzhou for building a pilot city for "Made in China 2025". Facilitating development of advanced manufacturing industry (such as automobile, electronic products, petrochemical, and electrical machinery and equipment) and modern service industry could be helpful in realizing a shift from the low end of the value chain into higher end.

\subsubsection{Zhuhai}

Being one of SPZs, Zhuhai borders Macao to the south and is a famous scenic-tourist city in China. In past decades, city's economic growth partly depends on the geographical proximity to Hong Kong and Macao. Its tertiary industry occupied $50 \%$ in city's GDP in 2015 , followed by secondary industry for $48 \%$, and primary industry for $2 \%[53]$. It is shown that Zhuhai still remained in industrialization mid-term stage. The total emissions appeared a fluctuating increase during past 17 years. Coal was still dominated contributor (79\%) of total emissions, followed by oil (13\%), gas (6\%) and industrial process (2\%). The emission characteristics of coal present a quick growth, while those of oil and gas augment slightly. The emissions by sectors had the similar tendencies. Energy production sectors and heavy manufacturing sectors experienced a fluctuating increase, respectively contributing to $48 \%$ and $37.8 \%$ of total emissions, while services sectors only accounted for $8 \%$. The manufacturing of home appliance, petrochemical industry and power supply were the city's pillar industries. GREE, the China's third largest electric appliance manufacturer, headquarters in Zhuhai.

In the past 20 decades, due to the strict environmental policies of local government, those enterprises with high pollution were forbidden and had to be moved to other cities (including Zhongshan, Jiangmen, Dongguan and Huizhou). This restricted the city's industrial development to a certain extent and led to the single industrial structure. Featured with coal-dominated and traditional heavy manufacturing-driven, Zhuhai produced seventeenth largest of total emissions (17Mt) with twelfth largest GDP (¥203 billion) and tenth lowest emission intensities $(0.85$ tonnes per $¥ 1,000)$ in 23 cities. More attention should be paid in transition from labour-intensive industries to high-tech industries and knowledge-intensive services, as well as development of cultural tourist industry.

\subsubsection{Meizhou}

Meizhou is located in northeast of Guangdong Province and features culture-oriented tourism. The tertiary industry accounted for $44 \%$ of city GDP, while tourist industry was the dominate contributor of tertiary industry. Owing to plenty of fruits and tea, the primary industry come to $20 \%$ of city GDP, followed by 
secondary industry (37\%)[53]. In addition, Meizhou is one of important electricity production base in Guangdong because of abounding with coal and hydro resources. Coal and industrial process were the primary $\mathrm{CO}_{2}$ emitters and contributed almost $90 \%$ of total emissions ( $67 \%$ for coal and $23 \%$ for process), followed by oil $10 \%$. The emissions of industrial process were mainly derived from cement production. Such a similar proportion could be seen in the emissions by sectors. Tobacco, power, building materials were the city's main industries. Energy production sectors and heavy manufacturing sectors respectively produced $55 \%$ and $34 \%$ of total emissions, occupying $90 \%$ of total emissions, while service sector only contributed 3\%. In virtue of the forceful policy actions of closing down backward production facilities of Guangdong province since 2012, small coal-fired power plants in Meizhou had to shut down and move to other towns, while a number of small cement plants faced to close down or switch to other products. Thus, emissions of coal appeared a sudden and sharp decline in 2014, while total emissions peaked in 2013 and dropped quickly later. Such the energy-intensive industrial structures lead to high total emissions and emission intensities. Meizhou emitted seventh largest emissions with fifth lowest GDP and second highest emission intensities in 23 cities. More endeavours should be made to optimise energy consumption mix and develop home building industry, electronic information industry and ecological tourism to achieve the low carbon and sustainable development.

\subsubsection{Shantou}

As one of SPZs, Shantou lies in the east of Guangdong province. It is one of significant port cities in the south-eastern coast of China and a pivot city along Marine Silk Road. Due to its location, city becomes one of biggest toy and gift production bases as well as stationery and garment processing bases. A great number of electric toys were produced in Shantou's factories and be sold to foreign regions. Toy and gift manufacture and clothing and textile industry are one of pillar industries of Shantou. The secondary industry occupied $52 \%$ of city GDP, followed by tertiary industry (43\%) and primary industry (5\%)[53]. For Shantou highly relies on the export trade (i.e., toy and clothes), export sliding affected by global financial crisis leaded to an obvious decrease in total emission in 2008.

As the units of Shantou power plant and Haimen power plant of China Huaneng Group were put into operation in 2005 and 2009[60], city's total emission presented a tendency of small growth in 2006, straight climb in 2009, abrupt drop in 2012 and then increased, finally reaching its peak in 2013. Such an obvious descend was attributed to the fact that with the implementing policy of encouraging large projects and discouraging small energy-inefficient power plants, small coal-fired power plants had been shut down instead of building large ultra-supercritical coal-fired units in 2011. Haimen coal-fired power plant units 3 and 4 and Fengsheng Shantou coal-fired power plant were the typical examples.

Coal accounted for the largest proportion (91\%) in total emissions in 21 cities, followed by oil (6\%) and industrial process (3\%). Similarly, energy production sectors contributed the greatest in the total emissions, coming to $86 \%$, while heavy and light manufacturing sectors respectively contributed $3 \%$ and $2 \%$. City's economic development was based on traditional, labour-intensive manufacturing with low added value products. Shantou produced eleventh largest emissions with ninth lowest GDP and eighth highest emission intensities in 23 cities. To achieve industrial transformation and low carbon development, the priority should be given to innovation financing mechanism as well as high-tech driven technological alteration 
and escalation toward more automation and intelligent practices.

\subsubsection{Yangjiang}

Yangjiang is located in the southwest coast of Guangdong Province and is one of famous coastal tourist cities of China. Because of plentiful supply of various seafood, grain, sugar, fruits and poultries, primary industry accounted for $16 \%$ of city GDP. Secondary industry and tertiary industry respectively contributed $45 \%$ and $39 \%[53]$. The city is also regarded as the capital of knives and scissors of China. Scissors, nonferrous metals, stainless steel and power supply are main industry of Yangjiang. Thus, energy production sectors and heavy manufacturing sectors are the greatest contributors, respectively accounting for $46 \%$ and $43 \%$, almost $90 \%$ of total emissions, while light manufacturing sectors and service sector only respectively occupied $1 \%$ and $4 \%$. From the view of emission by energy types, coal was main contributor and come to $70 \%$ of total emissions, followed by industrial process (21\%), oil (9\%) and gas (1\%). Total city emissions underwent a rapid increase within past 17 years. The acceleration points of the growth curves occurred in 2009, and 2014. Such unusual variations differ from most cities due to the fact that Huaxia Yangxi coal-fired power plant Units 1 and $2(2 \times 600 \mathrm{MW})$ were put into operation in 2009, while Units 3 and $4(2 \times 660 \mathrm{MW})$ began production in 2013 [61]. Units 5 and $6(2 \times 1240 \mathrm{MW})$ are under construction and will be finished in 2018[62].

Yangjiang has become a significant power production base to alleviate power demand-supply challenges within Guangdong Province. As one of biggest nuclear power stations, Yangjiang nuclear power station (total planning capacity $6 \times 1080 \mathrm{MW}$ ) is situated here[63]. The four units have come into service between 2014 and 2017, while last two units will be operational in 2019[64, 65]. The annual electricity generation of six units will come to 48 million MWh, corresponding to Hong Kong's electricity consumption in the whole year. Yangjiang emitted sixteenth largest emissions with seventh lowest GDP and seventh highest emission intensities. Technological transformation should be given priority and traditional heavy manufacturing should be gradually shifted to advanced equipment manufacturing industry.

\section{Conclusions and policy recommendations}

As the one of the China's current key economic development strategy, Guangdong-Hong Kong-Macao Greater Bay Area (GBA) is expected to be the world's largest bay area and plays significant roles in promoting world's low-carbon and sustainable development, as well as the Belt and Road initiative. In this study, this is the first attempt to compile $\mathrm{CO}_{2}$ emission inventory of $11 \mathrm{GBA}$ cities and their surroundings based on IPCC territorial emission accounting approach, which are consistent and comparable with the national and provincial inventories. $\mathrm{CO}_{2}$ emissions inventories have been constructed by 17 fossil fuels, 47 socio-economic sectors, and 7 industrial processes in order to identify cities' key emission contributors and different emission characteristics. The emission inventories provide robust, self-consistent, transparent, and comparable data support for low-carbon policy-making, mitigation progress monitoring of GBA and their surroundings, as well as further emissions-related studies at a city-level. The low-carbon development pathways are designed based on current emission characteristic, urbanisation process, industrial maturity and resource availability. The low-carbon roadmaps for GBA cities and their surroundings also provide a benchmark for other developing countries/cities to adapting changing climate 
and achieve sustainable development.

Results indicates that (a) total emissions increased from $426 \mathrm{Mt}$ in 2000 to $610 \mathrm{Mt}$ in 2016, while emissions of GBA cities increased rapidly by 7\% over 2000-2011 and peaked in 2014 (334 Mt); (b) among 23 cities, Guangzhou, Shaoguan, Hong Kong are top three emitters, while Macao, Shenzhen and Hong Kong have top three lowest emission intensity in the country; (c) GBA emitted $4 \%$ of total national emissions and contributed $13 \%$ of national GDP with less than a third (29\%) of national emission intensities and less than three-quarters (73\%) of national per capita emissions; (d) other cities supported GBA cities with raw materials, processing products, power and labour, emitting $3 \%$ of total national emissions and occupying $2 \%$ of national GDP with medium national emission intensity level; (e) raw coal and diesel oil are the first and second contributors of total emissions, while total emission of coal and oil respectively peaked in 2014 (157 Mt) and 2008 (107 Mt); (f) energy production and heavy manufacturing sector respectively were the first $(39 \%)$ and second (20\%) contributors of total emissions of industry sector, while tertiary industry contributed $30 \%$; (g) high-tech industry sector was particularly vulnerable and highly influenced by global financial crisis, its emission slump occurs in 2008.

Emissions characteristics of cities also show that (a) for Guangzhou and Shenzhen with high level of urbanisation and efficient transport system, oil is the main $\mathrm{CO}_{2}$ emitter and services sectors exceed energy production sectors became the biggest contributor; (b) for Zhongshan and Shenzhen with cleaner energy mix, gas accounts for the top two largest proportion of total emissions in 21 cities; (c) Shenzhen, Guangzhou, Hong Kong and Macao contributed higher GDP with better industrial structure and lowest emission intensities; (d) Zhuhai, Foshan, Jiangmen, Zhaoqing, Dongguan, Meizhou, Shantou, Shanwei, and Yunfu are industrial-driven cities, coal and energy production sectors are the dominated contributor of total emissions; (e) most of GBA cities are experiencing the shift from an industrial economy to a service economy, while Hong Kong, Shenzhen, Foshan and Huizhou reached their peak emissions and Guangzhou, Dongguan and Jiangmen remained decreasing emission tendencies; ( $f$ ) for coal-dominate cities (i.e. Zhuhai, Zhaoqing, Yangjiang, Shanwei, Shaoguan, Zhanjiang) in mid-term industrialization, total emissions experience soaring increases.

In order to achieve low-carbon energy transition and emission reduction of GBA and their surroundings, energy system optimization should be given priority. A series of energy project investments have been carried out to diversify power generation mix by clean energy and renewable energy. Nowadays, there are 10 units of nuclear power (Daya Bay, Ling'ao phase I, Ling'ao phase II, Yanjiang) in operation in Guangdong Province. Nuclear power contributes $18 \%$ electricity of Guangdong Province with $10 \%$ total installed capacity of the whole province[66]. Yangjiang pumped storage power plant (planning capacity 2400MW) is under constructed and will be gone into operation in 2021[67]. Yangjiang Nanpeng Island offshore wind farm (400MW) and Yangjiang Shapa offshore wind farm (300MW) was approved and will be come into service in 2020[68]. Secondly, industrial structure transformation and upgrading towards high-tech and knowledge-intensive industries, as well as modern service industry play significant roles in cities' economic development and emission intensity reduction. Due to the differences in resources availability, industrial structure, industrialization phrase and economic base, as well as administration partitioning of 23 cities, more government support are required to overcome institutional, technical and economic barriers to develop industrial clusters of bay area to achieve low-carbon coordinated development with 
complementary advantages and resource sharing. Thirdly, public consumer behaviour needs be guided towards low-carbon and sustainable lifestyle change, such as extensive utilisation of new energy and hightech energy-saving products.

This study has some limitations. For example, some cities' emission inventories in individual years are missing due to lack of energy consumption data, which lead to the uncertainties of results. Due to the unavailable energy data of Hong Kong and Macao, emission inventories of two special administrative regions cannot be complied. We collected their total emissions from EDGAR directly. Due to lack of emissions by energy types and sectors, energy types, sectors and activities responsible of Hong Kong and Macao cannot be identified. Further research will be focused on data investigation to improve the data quality. In addition, several mitigation scenarios with long-term mitigation options (i.e., develop local applicable renewable energy technologies, implement carbon capture, utilization and storage) will be developed to discuss the optimised mitigation pathways. Multi-criteria decision analysis will be applied to identify the cost-effective mitigation pathways as well as assess co-benefits of emission mitigation of GBA urban agglomeration in the future work. It will be helpful for exploring the role and emission mitigation potential of regional cooperation for GBA cities as well as cities along "Belt and Road".

\section{Acknowledgements}

All the data and results can be download freely from China Emission Accounts and Datasets (CEADs) at http://www.ceads.net. This work was supported by the Natural Science Foundation of China (71704029), Humanities and Social Science Foundation in Ministry of Education of China (16YJCZH162), Guangzhou Planning Project of Social Science (2016GZQN25), and the New Pearl River Star Program of Guangzhou City (201610010035).

\section{Appendix A. Supplementary tables}

Table S1 Fossil fuel types and emission factors used in this study

Table S2 Industry processes involved in this study and related emission factors

Table S3 Sectoral categories of the NAQSIQ

\section{Appendix B. Supplementary figures}

Figure S1 Total emissions by energy types and sectors of 6 key cities

\section{Reference}

[1] IEA. Global Energy \& CO2 Status Report 2017. International Energy Agency; 2018.

[2] Carrie M. Lee PE. What impact can local economic development in cities have on global GHG emissions? assessing the evidence. Cities: Impact On Global GHG Emissions: Stockholm Environment Institute; 2014.

[3] Guan D, Mi Z, Liu Z, Liu J, Viguié V, Fromer N, et al. Cities: the core of climate change mitigation. Journal of Cleaner Production. 2017.

[4] Shan Y, Guan D, Liu J, Mi Z, Liu Z, Liu J, et al. Methodology and applications of city level CO2 emission accounts in China. Journal of Cleaner Production. 2017;161:1215-25. 
[5] Shan Y, Guan D, Zheng H, Ou J, Li Y, Meng J, et al. China CO2 emission accounts 1997-2015. Scientific data. 2018;5:170201.

[6] IEA. World energy outlook 2008. France: International Energy Agency; 2008.

[7] Rosenzweig C, Solecki W, Hammer SA, Mehrotra S. Cities lead the way in climate-change action. Nature. 2010;467:909.

[8] IEA. Energy technology perspectives 2016 towards sustainable urban energy systems. International Energy Agency; 2016.

[9] Shan Y. GD, Hubacek K. , Z Zheng B., Davis S. J. , Jia L., Liu J., Liu Z., Fromer N., Mi Z., Meng J., Deng X, Li Y., Schroeder H. , Weisz H., Schellnhuber H. J. City-level climate change mitigation in China. . Science Advances. 2018;4:eaaq0390.

[10] SPUR. Fossil-free bay area: a cleaner future for the region's energy. San Francisco Bay Area Planning and Urban Research Association; 2016.

[11] Dodman D. Blaming cities for climate change? An analysis of urban greenhouse gas emissions inventories. Environ Urbanization. 2009;21:185-201.

[12] Kennedy C. SJ, Gasson B., Hansen Y. ,. Methodology for inventorying greenhouse gas emissions from global cities. Energy Policy. 2010;38:4828-37.

[13] Kennedy CA, Ramaswami, A., Carney, S., Dhakal, S.,. Greenhouse gas emission baselines for global cities and metropolitan regions. In: Agenda CaCCRtaU, editor.2011. p. 15-54.

[14] UNFCCC. Paris Agreement. 2015.

[15] Shan Y, Liu J, Liu Z, Xu X, Shao S, Wang P, et al. New provincial CO 2 emission inventories in China based on apparent energy consumption data and updated emission factors. Applied Energy. 2016;184:742-50.

[16] Dai HC MP, Xie XX, Xie Y, Masui T. Closing the gap? Top-down versus bottom-up projections of China's regional energy use and CO2 emissions. Applied Energy. 2016;162:1355-73.

[17] Bin Ye JJ, Changsheng Li, Lixin Miao, Jie Tang. Quantification and driving force analysis of provincial-level carbon emissions in China. Applied Energy. 2017;198:223-38.

[18] Hillman T, Ramaswami, A. Greenhouse gas emission footprints and energy use benchmarks for eight US cities. Environ Sci Technol. 2010;44:1902-10.

[19] Brondfield MN, Hutyra, L.R., Gately, C.K., Raciti, S.M., Peterson, S.A.,. Modeling and validation of on-road CO2 emissions inventories at the urban regional scale. Environmental Pollution. 2012;170:113-23.

[20] Sugar L, Kennedy C, Leman E. Greenhouse gas emissions from chinese cities. Journal of Industrial Ecology. 2012;16:552-63.

[21] Kennedy C, Ibrahim, N., Hoornweg, D. Low-carbon infrastructure strategies for cities. Nat Clim Change. 2014;4: 343-6.

[22] Creutzig F, Baiocchi, G., Bierkandt, R., Pichler, P.P., Seto, K.C. Global typology of urban energy use and potentials for an urbanization mitigation wedge. Proc Natl Acad Sci USA 2015;112 6283-8.

[23] Mi Z, Zhang Y, Guan D, Shan Y, Liu Z, Cong R, et al. Consumption-based emission accounting for Chinese cities. Applied Energy. 2016;184:1073-81.

[24] Markolf SA, Matthews HS, Azevedo IL, Hendrickson C. An integrated approach for estimating greenhouse gas emissions from 100 US metropolitan areas. Environmental Research Letters. 2017;12:024003.

[25] Dhakal S. Urban energy use and carbon emissions from cities in China and policy implications. Energy Policy. 2009;37:4208-19. 
[26] Liu Z, Liang S, Geng Y, Xue B, Xi F, Pan Y, et al. Features, trajectories and driving forces for energy-related GHG emissions from Chinese mega cites: the case of Beijing, Tianjin, Shanghai and Chongqing. Energy. 2012;37:245-54.

[27] Xu X, Huo H, Liu J, Shan Y, Li Y, Zheng H, et al. Patterns of CO 2 emissions in 18 central Chinese cities from 2000 to 2014. Journal of Cleaner Production. 2018;172:529-40.

[28] Wang S, Liu X. China's city-level energy-related CO2 emissions: Spatiotemporal patterns and driving forces. Applied energy. 2017;200:204-14.

[29] SC. Greater Bay Area new highlight in Chin's economy. The State Council of The People's Republic of China; 2017.

[30] XFA. What Guangdong-Hong Kong-Macao Greater Bay Area will bring for investors? Beijing: Xinhua Finance Agency; 2018.

[31] SCC. Greater Bay Area new highlight in China's economy. The State Council of the People's Republic of China; 2017.

[32] NBS. China Statistical Yearbook 2017. Beijing: China Statistical Press; 2017.

[33] BAAQMD. Bay Area Emissions Inventory Summary Report: Greenhouse Gases Base Year 2011. Bay area air quality management district 2015.

[34] Fairley D FM. Top-down methane emissions estimates for the San Francisco Bay Area from 1990 to 2012. Atmospheric Environment. 2015;107:9-15.

[35] IPCC. IPCC Guidelines for National Greenhouse Gas Inventories. Hayama, Japan: Institute for Global Environmental Strategies (IGES); 2006.

[36] NDRC. Guildelines for provincial greenhouse gas inventories. 2011.

[37] Peters GP, Weber C, Liu J. Construction of Chinese energy and emissions inventory. Trondheim, Norway: Norwegian University of Science and Technology; 2006.

[38] Liu Z, Guan D, Wei W, Davis SJ, Ciais P, Bai J, et al. Reduced carbon emission estimates from fossil fuel combustion and cement production in China. Nature. 2015;524:335-8.

[39] NAQSIQ. National industries classification (GB/T 4754-2011). 2011.

[40] NDRC. Initial national communication on climate change. Beijing, China: China Planning Press; 2004.

[41] NDRC. The people's republic of China second national communication on climate change. 2012.

[42] NDRC. First biennial update report on climate change. 2016.

[43] NBS. China energy statistical yearbook 2001-2017. Beijing, China: China Statistics Press; 2001-2017.

[44] Janssens-Maenhout G, Crippa, M., Guizzardi, D., Muntean, M., Schaaf, E., Olivier, J.G.J., Peters, J.A.H.W., Schure, K.M. Fossil CO2 and GHG emissions of all world countries. Luxembourg: Publications Office of the European Union; 2017.

[45] C\&SD. Gross Domestic Product (GDP). 28 02,2018 ed. Hong Kong: Census and Statistics Department, Hong Kong Special Administrative Region; 2018.

[46] DSEC. Statistics Database. Macao: Government of Macao Special Administrative Region Statistics and Census Service; 2018.

[47] NBS. China Statistical Yearbook 2016. Beijing: China Statistical Press; 2016.

[48] CFETS. RMB exchange rate Beijing: China Foreign Exchange Trade System; 2018.

[49] Zhou Y, Li YP, Huang GH. Planning sustainable electric-power system with carbon emission abatement through CDM under uncertainty. Applied Energy. 2015;140:350-64. 
[50] Zhang Q. SDG, He K., Wang Y., Richter A., Burrows J. P., Uno I., Jang C. J., Chen D., Yao Z. NOx emission trends for China, 1995-2004: The view from the ground and the view from space. Journal of Geophysical Research: Atmospheres 2007; 112:1-18.

[51] Zhao Y. WS, Duan L., Lei Y., Cao P., Hao J. . Primary air pollutant emissions of coal-fired power plants in China: Current status and future prediction. Atmospheric Environment. 2008;42:8442-52.

[52] Wu Y. SDS, Wang S., Hao J. . Uncertainties in estimating mercury emissions from coal-fired power plants in China. Atmospheric Chemistry and Physics. 2010;10: 2937-46

[53] GMBS. Guangdong Statistical Yearbook 2016. Guangzhou: China Statistics Press; 2016.

[54] MPS. Motor vehicles in China exceeded 300 million by the end of March, 2017. Traffic Management Bureau of the Ministry of Public Security of China; 2017.

[55] SZTB. Shenzhen completes switch to fully electric bus fleet. Shenzhen: Shenzhen's transport committee; 2017.

[56] Zhou Y, Li YP, Huang GH. Integrated modeling approach for sustainable municipal energy system planning and management - A case study of Shenzhen, China. Journal of Cleaner Production. 2014;75:143-56.

[57] CGN. Daya Bay Nuclear Power Base China General Nuclear Power Group; 2018.

[58] CLP. Guangdong Daya Bay Nuclear Power Station. China Light and Power Group; 2018.

[59] Zhou Y, Li YP, Huang GH. A robust possibilistic mixed-integer programming method for planning municipal electric power systems. International Journal of Electrical Power \& Energy Systems. 2015;73:757-72.

[60] SMG. Generating Unit of Huaneng Haimen Power Plant Connected to Grid for Power Generation. Shantou Municipal Government; 2009.

[61] YAOF. Guangdong Yangxi Zhujiang power station. Administration of Ocean and Fisheries of Yangjiang; 2016.

[62] GDDRC. Huaxia Yangxi coal-fired power plant Units 5 and 6 Guangzhou: Guangdong Provincial Development and Reform Commission; 2018.

[63] CNEC. Yangjiang NPP in Guangdong Province. China Nuclear Engineering \& Construction Group; 2011.

[64] WNN. Fourth Yangjiang unit enters commercial operation. World nuclear news; 2017.

[65] CGN. Yangjiang NPP Unit 5 readies for commercial operation. China General Nuclear Power Group; 2018.

[66] Long JG. Nuclear power will provide stable power for Guangdong-Hong Kong-Macao Greater Bay Area (in Chinese). 2017.

[67] Goess G. Growth of renewable energies in China. Energy Brainpool 2015.

[68] CGN. Construction of China's largest single offshore wind farm progresses. China General Nuclear Power Group; 2018. 